\title{
Pancreatic Injury and Coronavirus Disease-2019
}

\author{
Gontar Alamsyah Siregar, Lukman Hakim Zain, Masrul Lubis*, Ilhamd Ilhamd, Taufik Sungkar, Imelda Rey, Darmadi Darmadi \\ Department of Internal Medicine, Division of Gastroenterohepatology, Faculty of Medicine, Universitas Sumatera Utara, \\ Medan, Indonesia
}

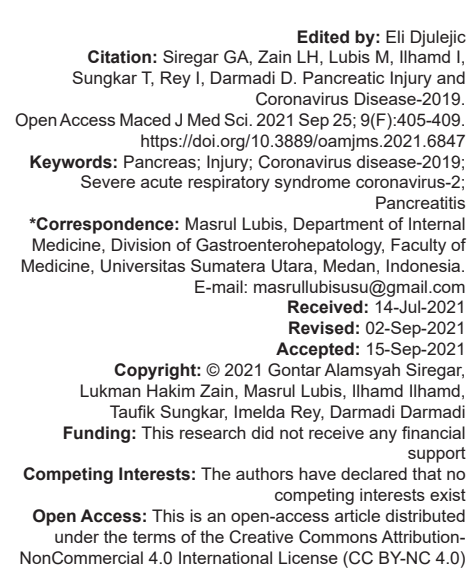

Introduction

Even though coronavirus disease 2019 (COVID-19) is considered as a lower respiratory tract infection, the disorder can induce dysfunction in a couple of organs, including kidney, heart, liver, gut, and pancreas. Different viral diseases, such as human immunodeficiency virus, mumps, cytomegalovirus, coxsackievirus $B$, and influenza $A(H 1 N 1)$, share the similar motive of acute pancreatic inflammation. The severe acute respiratory syndrome coronavirus-2 (SARS-CoV-2) as the main etiology for COVID-19 comprises angiotensin-converting enzyme 2 (ACE 2) receptors for invading the tissue cells and hence spreads through the barrier respiratory tract. The clinical signs of patients with COVID-19 normally include fever, cough, fatigue, and a few patients have proven signs of gastrointestinal disturbance [1], [2], [3], [4]. For the Southeast Asia region, there are around 735,854 confirmed cases with 20,621 deaths. Indonesia has reported around 51,095 additional confirmed cases with 3720 deaths, to $1,837,126$ confirmed cases as of 3 June 2021 and on the same day in North Sumatra province, 2323 confirmed cases were reported [5].
Pancreatic injury is an inflammatory situation of the exocrine pancreas, precipitated commonly by the presence of gallstones and alcohol intake. Acinar cell injury and impaired zymogen secretion leading to intrapancreatic protease activation underlie this sickness. Diagnosis requires out of three criteria: Typical records multiplied serum amylase or lipase over 3 times the higher restrict of normal for the laboratory reference range and suggestive imaging findings. However, acute liver injury in patients with COVID-19 is independently associated with detrimental clinical effects. There is lack of research about the influence of SARS-CoV-2 in pancreatic injury. Herein this takes a look at discusses of the modern evidence for the effect of COVID-19 on the pancreatic feature [6].

We here provide a concise evaluation of the relevant posted articles and features summarized the general incidence, costs for pancreatic involvement in COVID-19, techniques to be adopted for the control of patients with pancreatic cancer, and those requiring a pancreatic surgical operation. The effect of COVID- 19 infection on pancreas transplant recipients has additionally been reviewed. 


\section{Methods}

Aliterature searching was conducted throughthe PubMed, Science Direct, Medline, and Google Scholar search engines for all applicable articles/abstracts in English. We used a search question built with the subsequent scientific difficulty heading (MeSH) phrases: ("severe acute respiratory tract syndrome- coronavirus 2019" OR "COVID-19" OR "coronavirus 2019" OR "SARS-CoV-2") AND ("pancreas" OR "pancreatitis" OR "hyperamylasemia" OR "pancreatic injury" OR "pancreatic damage" OR "pancreatic disturbance"). We involved all literatures including literature review, case report, original article, systematic review, and metaanalysis. The reference list of the papers, webpages of fundamental gastroenterology and hepatology journals, and websites of the World Health Organization (WHO), and Centre for Disease Control and Prevention courses were reviewed and all applicable information was extracted with the aid of the authors and was framed into a story overview. A total of 17 literatures were gathered as presented in Table 1.

Table 1: Gathered literatures and their main findings

\begin{tabular}{|c|c|c|c|}
\hline $\begin{array}{l}\text { Citation } \\
\text { number }\end{array}$ & Authors & $\begin{array}{l}\text { Publication } \\
\text { year }\end{array}$ & Main findings \\
\hline 1 & Samanta et al. & 2020 & $\begin{array}{l}\text { Elevation of pancreatic enzymes is observed in } \\
\text { COVID-19 particularly in severe cases }\end{array}$ \\
\hline 6 & Ghosh et al. & 2020 & $\begin{array}{l}\text { Elevation of pancreatic enzymes, abnormal } \\
\text { pancreatic imaging, and severe pancreatitis in } \\
\text { a patient with COVID-19 }\end{array}$ \\
\hline 7 & Wang et al. & 2020 & $\begin{array}{l}\text { Potential mild pancreatic injury in COVID-19 } \\
\text { pneumonia may be caused direct viral } \\
\text { involvement or secondary from systemic } \\
\text { inflammation }\end{array}$ \\
\hline 8 & $\begin{array}{l}\text { de-Madaria } \\
\text { et al. }\end{array}$ & 2020 & $\begin{array}{l}\text { Gastroenteritis in COVID- } 19 \text { which is due to } \\
\text { inflammation causes the elevation of pancreatic } \\
\text { enzymes }\end{array}$ \\
\hline 9 & Goyal et al. & 2021 & $\begin{array}{l}\text { Elevated lipase enzyme is observed in } 11.7 \% \\
\text { COVID- } 19 \text { patients. Most of pancreatic injuries } \\
\text { are mild to moderate }\end{array}$ \\
\hline 10 & Liu et al. & 2020 & $\begin{array}{l}\text { The level of ACE2 mRNA in pancreas is higher } \\
\text { compared to lung. Both exocrine gland and } \\
\text { islet express ACE2. Pancreatic enzymes are } \\
\text { elevated mostly in severe COVID-19 cases }\end{array}$ \\
\hline 11 & $\begin{array}{l}\text { de-Madaria } \\
\text { et al. }\end{array}$ & 2020 & $\begin{array}{l}\text { The presence of ACE2 in pancreas is } \\
\text { hypothesized as the connecting point between } \\
\text { COVID-19 and pancreatic injury }\end{array}$ \\
\hline 12 & Mukherjee et al. & 2020 & $\begin{array}{l}\text { Pancreatic cells highly express ACE2, bridging } \\
\text { the relationship between elevated pancreatic } \\
\text { enzymes and COVID-19 }\end{array}$ \\
\hline 14 & $\begin{array}{l}\text { McNabb-Baltar } \\
\text { et al. }\end{array}$ & 2020 & $\begin{array}{l}\text { A total of } 12.1 \% \text { COVID- } 19 \text { patients experience } \\
\text { hyperlipasemia. Hyperlipasemia is not } \\
\text { associated with poor morbidity and mortality }\end{array}$ \\
\hline 15 & de Sa et al. & 2021 & $\begin{array}{l}\text { Several mechanisms underlying acute } \\
\text { pancreatitis in COVID-19 patients are direct } \\
\text { virus-mediated injury, systemic inflammation, } \\
\text { and drug-induced }\end{array}$ \\
\hline 17 & Wifi et al. & 2021 & $\begin{array}{l}\text { Pancreatitis is observed in a } 72 \text {-year-old } \\
\text { female COVID-19 patient }\end{array}$ \\
\hline 18 & AlHarmi et al. & 2021 & $\begin{array}{l}\text { Acute pancreatitis is reported in a } 52 \text {-year-old } \\
\text { female COVID-19 patient }\end{array}$ \\
\hline 19 & Singla et al. & 2020 & $\begin{array}{l}\text { Elevated serum amylase and lipase levels are } \\
\text { the sign of pancreatic involvement in COVID-19 } \\
\text { patients. Pancreatic islet cell damage may } \\
\text { disturb blood sugar level and predispose to } \\
\text { future DM }\end{array}$ \\
\hline 20 & Patnaik et al. & 2020 & $\begin{array}{l}\text { Acute pancreatitis is diagnosed in a } 29 \text {-year-old } \\
\text { male COVID-19 patient }\end{array}$ \\
\hline 21 & Alves et al. & 2020 & $\begin{array}{l}\text { Acute pancreatitis is reported in a } 56 \text {-year-old } \\
\text { female COVID-19 patient }\end{array}$ \\
\hline 22 & Kandasamy & 2020 & $\begin{array}{l}\text { Acute pancreatitis is reported in a } 45 \text {-year-old } \\
\text { female COVID- } 19 \text { patient }\end{array}$ \\
\hline 23 & Gupta et al. & 2021 & $\begin{array}{l}\text { Acute pancreatitis is observed in a } 25 \text {-year-old } \\
\text { female COVID- } 19 \text { patient }\end{array}$ \\
\hline
\end{tabular}

\section{SARS-CoV-2 at a glance}

Coronavirus is a member of a family of virus responsible for a huge fraction of the human common cold. They are enveloped, positive, single-stranded RNA viruses that belong to the Coronaviridae family and the Nidovirales order. The most frequently encountered types inflicting respiratory infections are 229E, NL63, OC43, and HKU1. However, the types which are zoonotic in starting place, can infect humans and lead to fatal disease, among which are SARS-CoV, Middle East Respiratory Syndrome- Coronavirus (MERS- CoV), and recently detected novel coronavirus-2019 (SARS- CoV- 2). The genomic structure of SAR- CoV-2 is $89 \%$ identic to bat SARS-like-CoVZXC21 and $82 \%$ identic to human SARS-CoV. The world has already witnessed pandemics of the former two lines, SARS (2002-2003) and MERS (2012). One-third of coronavirus is determined as SARS-CoV-2 with the aid of the global Committee on Taxonomy of Viruses and later renamed as COVID-19 by the WHO [7].

Electron micrograph pictures find the virus' diameter to be $60-140 \mathrm{~nm}$ and the appearance of a sun corona (a crown-like) due to the presence of spikes (diameter of 9-12 nm). A spike glycoprotein (S glycoprotein) attaches the virus to the host cellular membrane and is a key element for host range restriction. The virus has been identified to have 3 subtypes: "A," "B," and "C" at the same time as "A" and " $C$ " subtypes have been mentioned from U.S. and Europe, while subtype " $\mathrm{B}$ " is discovered predominantly in East Asia [6].

\section{Coronavirus-19 and pancreatic injury} cases

A few associations between COVID-19 and acute pancreatitis were suggested. Data showed that a proportion of patients admitted to the intensive care unit with COVID-19 were also recognized with acute pancreatitis. In a single observational study in China, of 67 patients with severe COVID-19, 12 patients $(17.9 \%)$ had elevated amylase levels, 11 patients (16.4\%) had elevated lipase tiers, and five patients $(7.5 \%)$ had abnormal imaging findings (focal enlargement of the pancreas or dilatation of the pancreatic duct). Similarly, $2 \%$ of patients with non-critical COVID-19 had increased lipase and amylase tiers [8]. In another report from China, elevated amylase tiers had been observed in 19 patients with COVID-19 admitted to the intensive care unit. In a cohort of 883 patients with COVID-19 in the United States, 32 patients met the criteria for diagnosis of pancreatitis. In another study in the United States, 14 (18.7\%) out of 75 patients with COVID-19 met the criteria for a diagnosis of pancreatic injury [9].

Although acute pancreatitis is not common in patients with COVID-19, four scases of acute pancreatitis were showed in three different studies after cautious exclusion of other factors, highlighting a probable role 
of COVID-19 as an etiological component for acute viral pancreatitis [10]. Elevated levels of pancreatic enzymes without medical evidence of pancreatitis were observed in patients with COVID- 19. Patients with COVID-19 might also experience symptoms related to excessive pancreatic enzyme levels, which include intestinal irritation, diabetes, and kidney injuries. Gastroenteritis is a reason for elevated pancreatic enzymes and we might define such elevation through raised intestinal permeability in response to inflammation, which promotes the reabsorption of macromolecules, including amylase and lipase [11].

In an observation in China of 52 patients with COVID-19, nine (17.3\%) patients had abnormal amylase or lipase levels, six of whom presented hyperglycemia without history of diabetes. SARS-CoV-2 infection of the exocrine pancreas can generate islet cell injury via the production of pro-inflammatory cytokines. Patients with SARS-CoV infection may develop diabetes at 3 years after recovery. This is caused by damage of islet cell from the infection. Since there are many similarities between SARS-CoV and SARS- CoV-2, pancreatic islet cell damage may also occur in COVID-19 [7]. The autopsy result from three patients with COVID-19 showed that a few pancreatic islet cells have degenerated with a normal exocrine pattern. Recently, a survey of 1122 hospitalized patients with COVID-19 showed out-of- control hyperglycemia in 257 of them. As a result, just like SARS-CoV infection, we can associate a pancreatic injury with COVID-19 [12].

\section{injury}

\section{Underlying pathogenesis of pancreatic}

Hypothesized to have originated from bats or pangolins, COVID-19 uses angiotensin converting enzyme 2 (ACE2) as a receptor akin to SARS-CoV. The pathogenesis for lung damage encompasses attachment of the virus to ACE2 receptor at the lung type 2 alveolar cells. As soon as the spike protein (S) attaches to the alveolar cells, it leads to a cytokine storm which leads to alveolar flooding and denudation of the liner epithelium, hampering oxygen exchange and manifesting clinically as ARDS [13]. This ACE2 receptor expression is not always the only gift inside the lungs but is also in abundance inside the esophageal epithelial cells, absorptive enterocytes of the ileum and colon, cardiovascular and renal tissues, and the pancreas. In reality, we had observed messenger RNA levels of ACE2 to be more abundant in the pancreas than in the lung. This explains the multi-organ tropism of the virus [14].

Coronaviruses including SARS-CoV and SARS-CoV-2 enter target cells through the ACE2 receptor. Therefore, the expression of ACE2 in any organ may additionally provide a pathway for SARS- CoV-2 infection to cause tissue damage. Unfortunately, ACE2 is expressed inside the exocrine glands and islets of the pancreas, and its expression is proportional to the severity of SARS-CoV-2 infection (Figure 1) [15]. Considerable expression of ACE2 in human pancreatic islets has been reported. In patients with severe COVID-19, the expression of ACE2 inside the pancreas at some levels can cause acute inflammation which prompted acute pancreatitis [16].

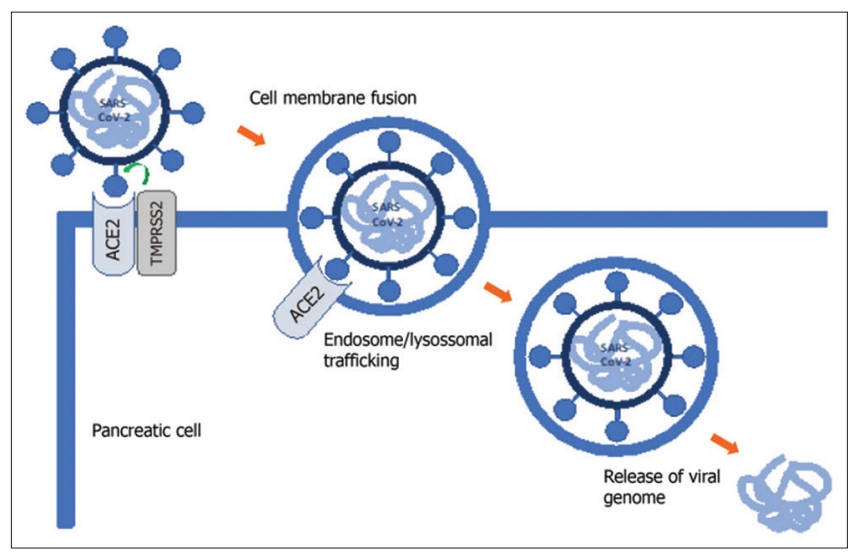

Figure 1: The role of ACE2 in the pathogenesis of pancreatic damage in patients with coronavirus disease-19 [15]

The spike protein (S) of SARS-CoV-2 engages ACE2 as the entrance receptor. It facilitates the cellular access with priming of the $S$ protein through transmembrane protease serine 2 (TMPRSS2) or different proteases. The presence of both ACE2 and TMPRSS2 is required for the virus access into the cell. In reality, single-cell RNA-sequencing research has proven that this co-expression is no longer the most effective pathway for the lung alveolar epithelial type 2 cells; however, the pathway is still prominent in diverse organs including the pancreatic cells [17]. The receptor affinity of SARS-CoV-2 to ACE2 is greater compared to SARS-CoV, which may explain the higher efficiency and stronger transmissibility of SARS-CoV-2. The binding of the virus to the ACE2 receptor mediates pancreatic injury. We have seen the dysregulated immune response and cytokine burst in severe COVID-19 infection with high levels of interleukin-6 (IL-6) which associated with the worse prognosis. We have cited that pancreatic injury is more prominent in severe compared to milder COVID-19 infection possibly as a result of the cytokine burst and immune dysregulation [18].

However, there are other workable reasons for pancreatic injury in patients with COVID-19. We have also mentioned acute pancreatitis as a damaging impact of lopinavir-ritonavir, a treatment for patients with COVID- 19. In addition, antipyretics, which the affected person may additionally have taken earlier than admission, can cause pancreatic injury. A moderate rise in blood pancreatic enzymes in patients with COVID19 can also results from culprits other than pancreatic injury. For intensive care unit clinicians making admission choices, predicting the severity of acute pancreatitis is crucial [19]. 
Nutritional problems are poor prognostic markers for many critical illnesses such as pancreatic injury, because of the higher possibility for the development of organ failure. Nutritional problems involve increased visceral adipose tissue, together with intra-pancreatic fat. In a situation of increased pancreatic enzymes in an episode of pancreatic damage, unsaturated fatty acids (UFAs) from the triglycerides in the adipocytes get released via hydrolysis and perpetuate fat necrosis in pancreatic injury. The unbuffered portion of the released UFAs ends in cytokine burst, organ failure, and end-organ damage. A similar pathogenetic mechanism of cellular injury by UFAs has been currently defined in COVID-19 infection and has been observed to be associated with mortality [15], [19].

Obesity is a risk factor for unfavorable prognosis in COVID-19 infection. As stated in advance, ACE2, expressed both in adipose tissue and pancreas, is a key receptor for the virus [20]. As a result, this pathway of virus-triggered lipotoxicity and cytokine storm can explain pancreatic damage. In reality, the cytokine profile of each pancreatic damage and COVID-19 infection has been determined to be comparable, with increased levels of IL-6, IL-8, and IL-10. In the later studies, SARS-CoV had been proven to be a reason for higher fasting plasma glucose levels and the damage of the pancreatic beta cells became incriminated as a predisposition for the development of "acute diabetes" [6].

The virus can also affect the glucose homeostasis through the $\mathrm{Na} / \mathrm{H}$ exchanger (NHE) and lactate pathways. While ACE2 is blocked; angiotensin II levels increase, which promotes NHE activity. This may lead to cellular hypoxia and elevation of reactive oxygen species production ensuing in endothelial damage and insulin resistance. Infection of the exocrine pancreas can lead to collateral damage to beta cells through inflammatory cytokines [21]. Disturbance of endocrine and exocrine pancreas may be caused by several factors. First, due to direct virus-mediated damage of the exocrine pancreas via the ACE2 receptors; second, the severe COVID-19 infection can lead to systemic inflammation and pancreatic injury; third, the virusmediated injury to the islet cells; fourth, damage through pro-inflammatory milieu through high levels of IL-1 $\beta$, monocyte chemoattractant protein-1, etc., and immune dysregulation; fifth, lipotoxicity from UFAs causing hyperlipidemia; and lastly, drug-induced pancreatic injury (because of non-steroidal anti-inflammatory drugs and corticosteroids) [22].

The interaction between COVID-19 and the pancreatic endocrine system complicates the state of affairs for patients with diabetes mellitus (DM) infected with the virus. Uncontrolled DM with related hyperglycemia has been identified to have a negative effect toward multiple morbidity and mortality. We can define this to be secondary to depressed innate immune response and exaggerated cytokine response in subjects with DM [3]. We hypothesized the relationship between the severity of infection and the glycosylated ACE2 receptors in the pulmonary epithelium. For that reason, elevated expression of receptors in the lung of subject with uncontrolled DM can aggravate binding of the virus and result in motive more severe disease. Furthermore, COVID-19 infection can worsen the glycemic control via damage to the pancreatic beta cells either directly through SARS-CoV-2 infection or through cytokine-mediated damage [23].

With available scoring systems, such as Ranson's rating, the updated Glasgow score, the harmless acute pancreatitis rating, and the bedside index for the severity of acute pancreatitis, one can predict the severity and mortality of acute pancreatitis at the first encounter of admission. Among them, Ranson's rating diagnostic accuracy on admission is higher for prediction of severity, organ failure, and mortality, primarily based on the clinical manifestation. We can use these scoring systems for predicting the severity and mortality of acute pancreatitis in patients with COVID-19 [10].

\section{Conclusion}

COVID-19 has broad spectrum of symptoms involving many organs such as pancreas. The prevalence of pancreatitis in patients with COVID-19 is low (<20\%). COVID-19 may damage pancreas by direct invasion of SARS-CoV-2, indirect inflammation from elevated pro-inflammatory cytokines production, and side effects of medications used to treat the disease. COVID-19 patients with obesity tend to have worse outcome of pancreatitis. As the result of pancreatic damage, DM may develop later after the recovery of COVID-19. Assessment of severity of pancreatitis using available scoring system may aid in managing pancreatitis in COVID-19 patients.

\section{References}

1. Samanta J, Gupta R, Singh MP, Patnaik I, Kumar A, Kochhar R Coronavirus disease 2019 and the pancreas. Pancreatology. 2020;20(8):1567-75. https://doi.org/10.1016/j.pan.2020.10.035 PMid:33250089

2. Ruslie RH, Darmadi D. Coronavirus disease-19 and menta health. Open Access Maced J Med Sci. 2020;8:268-71. https:// doi.org/10.3889/oamjms.2020.5304

3. Siregar GA, Siregar GP, Darmadi D, Ruslie RH. Coronavirus disease-19 and liver injury. Open Access Maced J Med Sci. 2020;8:154-7. https://doi.org/10.3889/oamjms.2020.5028

4. Siregar GA, Siregar GP, Darmadi D. Gastrointestinal aspects 
of COVID-19: A review. Open Access Maced J Med Sci. 2020;8:52- 4. https://doi.org/10.3889/oamjms.2020.4891

5. Negara MR, Krissanti I, Pradini GW. Analysis of SARS-CoV-2 nucleocapsid protein sequence variations in ASEAN countries. Med J Indones. 2021;30(2):89-95. https://doi.org/10.13181/mji. oa. 215304

6. Ghosh A, Gupta V, Misra A. COVID19 induced acute pancreatitis and pancreatic necrosis in a patient with Type 2 diabetes. Diabetes Metab Syndr. 2020;14(6):2097-8. https://doi. org/10.1016/j.dsx.2020.10.008

PMid:33152555

7. Wang $\mathrm{F}$, Wang $\mathrm{H}$, Fan J, Zhang $\mathrm{Y}$, Wang $\mathrm{H}$, Zhao Q. Pancreatic injury patterns in patients with coronavirus disease 19 pneumonia. Gastroenterology. 2020;159(1):367-70. https://doi. org/10.1053/j.gastro.2020.03.055

PMid:32247022

8. de-Madaria E, Siau K, Cárdenas-Jaén K. Increased amylase and lipase in patients with COVID-19 pneumonia: Don't blame the pancreas just yet? Gastroenterology. 2021;160(5):1871. https://doi.org/10.1053/j.gastro.2020.04.044

PMid:32330475

9. Goyal H, Sachdeva S, Perisetti A, Mann R, Inamdar S, Tharian B. Hyperlipasemia and potential pancreatic injury patterns in COVID-19: A marker of severity or innocent bystander? Gastroenterology. 2021;160(3):946-8. https://doi. org/10.1053/j.gastro.2020.10.037

PMid:33129845

10. LiuF,LongX,ZhangB,ZhangW,ChenX,ZhangZ.ACE2expression in pancreas may cause pancreatic damage after SARS-CoV-2 infection. Clin Gastroenterol Hepatol. 2020;18(9):2128- 30. https://doi.org/10.1101/2020.02.28.20029181 PMid:32334082

11. de-Madaria E, Capurso G. COVID-19 and acute pancreatitis: Examining the causality. Nat Rev Gastroenterol Hepatol. 2020;18:3-4. https://doi.org/10.1038/s41575-020-00389-y

12. Mukherjee R, Smith $A$, Sutton R. Covid-19 related pancreatic injury. Br J Surg. 2020;107(7):e190. https://doi.org/10.1002/ bjs. 11645 PMid:32352160

13. Petrone P, Alvarez SM, Perez MG, Esparragon JC, Marini CP. Pancreatic trauma: Management and literature review. Cir Esp. 2017;95(3):123-30. https://doi.org/10.1016/j. cireng.2016.05.012

\section{PMid:27480036}

14. McNabb-Baltar J, Jin DX, Grover AS, Redd WD, Zhou JC Hathorn KE, et al. Lipase elevation in patients with COVID- 19. Am J Gastroenterol. 2020;115(8):1286-8. https://doi. org/10.14309/ajg.0000000000000732 PMid:32496339

15. de Sa TC, Soares C, Rocha M. Acute pancreatitis and COVID-19: A literature review. World J Gastrointest Surg. 2021;13(6):574-84. PMid:34194615

16. Cieslewicz A, Dudek M, Krela-Kazmierczak I, Jabłecka A, Lesiak M, Korzeniowska K. Pancreatic injury after COVID-19 vaccine-a case report. Vaccines. 2021;9(6):576. https://doi. org/10.3390/vaccines 9060576 PMid:34205898

17. Wifi M, Nabil A, Awad A, Eltatawy R. COVID-induced pancreatitis: Case report. Egypt J Intern Med. 2021;33(1):10. https://doi.org/10.1186/s43162-021-00039-y PMid:33716498

18. AlHarmi RA, Fateel T, Adnan JS, AlAwadhi K. Acute pancreatitis in a patient with COVID-19. BMJ Case Rep. 2021;14:e239656. https://doi.org/10.1136/bcr-2020-239656

19. Singla V, Arora A. Hepatobiliary and pancreatic manifestations of coronavirus disease 2019. J Dig Endosc. 2020;11(1):21-3.

20. Patnaik RN, Gogia A, Kakar A. Acute pancreatic injury induced by COVID-19. IDCases. 2020;22:e00959. https://doi. org/10.1016/j.idcr.2020.e00959

PMid:32934906

21. Alves AM, Yvamoto EY, Marzinotto MA, Teixeira AC, Carrilho FJ. SARS-CoV-2 leading to acute pancreatitis: An unusual presentation. Braz J Infect Dis. 2020;24(6):561-4. https://doi. org/10.1016/j.bjid.2020.08.011

PMid:32961108

22. Kandasamy S. An unusual presentation of COVID- 19: Acute pancreatitis.Ann Hepatobiliary PancreatSurg. 2020;24(4):539-41. https://doi.org/10.14701/ahbps.2020.24.4.539 PMid:33234760

23. Gupta A, Bansal DP, Rijhwani P, Singh V. A case report on acute pancreatitis in a patient with coronavirus disease 2019 (COVID-19) pneumonia. Cureus. 2021;13(4):14628. https://doi. org/10.7759/cureus. 14628

PMid:34046267 